\title{
Cultural Differentiation of Negotiating Agents
}

\author{
Gert Jan Hofstede • Catholijn M. Jonker • \\ Tim Verwaart
}

\begin{abstract}
Negotiations proceed differently across cultures. For realistic modeling of agents in multicultural negotiations, the agents must display culturally differentiated behavior. This paper presents an agent-based simulation model that tackles these challenges, based on Hofstede's model of national cultures. The context is a trade network for goods with a hidden quality attribute. The negotiation model is based on the ABMP negotiation architecture and applies a utility function that includes market value, quality preference and risk attitude. The five dimensions of Hofstede's model are the basis for the modification of ABMP parameters and weight factors in the utility function. The agents can observe each other's group membership and status. This information is used, along with the indices of Hofstede's dimensions, to differentiate behavior in different cultural settings. The paper presents results of test runs that verify the implementation of the model. The model helps to explain behaviors of actors in international trade networks. It proves that Hofstede's dimensions can be used to generate culturally differentiated agents. Further validations of the model with case studies from literature and experiments have yet to be conducted. Extensions can make this model a useful tool for training traders who engage in cross-cultural negotiation and for implementation in negotiation support systems.
\end{abstract}

G. J. Hofstede

Wageningen University, Hollandseweg 1, 6706 KN Wageningen, The Netherlands

C. M. Jonker

Delft Technical University, Mekelweg 4, 2628 CD Delft, The Netherlands

T. Verwaart (ه)

LEI Wageningen UR, Postbus 29703, 2502 LS Den Haag, The Netherlands

e-mail: tim.verwaart@wur.nl 
Keywords Multi-agent simulation · Culture · Bargaining · Negotiation · Trade network

\section{Introduction}

Anybody with experience in international trade knows that bargaining practices differ across the world. Multinational companies sometimes work with different price lists for different countries. To give just one example: whereas German buyers want to know exactly how much the products cost, Arabs need to have room for bargaining. In order to sell at the same price, the selling company needs to adapt its offer to the varying bargaining practices. This means that a single piece of advice about how to bargain, or a single model to describe bargaining, are obviously not valid across the world unless culture is taken into account.

'Culture' is a notion with many meanings, some of which are contested in some disciplines. However, the leading paradigm today is widely accepted and used in both practice and academia. According to it, culture refers to the unwritten rules of society. Culture is that which makes a group cohesive by smoothing communication. It is a phenomenon that is specific to a group, not to an individual. Its essence is unconscious shared systems of values, and it is transmitted in early youth through example and education. As a result it is stable across centuries in spite of huge changes in environment and technology. Cultural differences show no signs of diminishing in the Information Age (Hofstede and Hofstede 2005).

Within the literature various basic dimensions can be found according to which societies differ from one another. Of these, the most widely used is Hofstede's model (Hofstede 2001), (Hofstede and Hofstede 2005). His work is accessible, sparse, and based on a very large, very well stratified sample that continues to give it great explanatory value. No other model matches society-level variables so well to date (Smith 2004).

This paper describes an agent-based model for bargaining in the context of trade. The agents follow common sense strategies such as maximizing gain, seeking good quality, and minimizing risk. But they also have models of how to behave in an appropriate manner. These models are based on Hofstede's five dimensions of culture. The challenge that we take up is the one posed by De Rosis et al. (2004), who suggested to investigate the feasibility of Hofstede's model for building culturally consistent agent characters. An agent-based model of bargaining in which the agents are cultured offers several promises. It can help understand the dynamics of international negotiations in trade. It could also serve as a training tool for aspiring international traders.

The paper first briefly introduces Hofstede's model of five dimensions of culture. Next, the ABMP (Agent-Based Market Place, Jonker and Treur 2001) negotiation model that we adopt is presented. We show how this model can be used in agentbased simulations. We also discuss the limited subset of negotiation situations that are considered in this article. In the third section we link culture and negotiation by describing the influence of each of Hofstede's dimensions of culture on negotiators' practices and preferences. This section sets the scene for the presentation of the rules for our cultured agents in the fourth section. Section five shows example runs with the 
model and discusses them. Finally we discuss the model and how to proceed, since this model forms the basis of future research and tools.

\section{Hofstede's Five Dimensions of Culture}

Each human society has found a different pattern of response to the problems of social life. In some societies, groups are permanent and close-knit while in others, group membership is volatile and voluntary. In some, leadership style is usually autocratic and in others, participative. Research has shown and repeatedly confirmed that basic tendencies to deal with a few central issues of social life are stable across the generations in societies (Hofstede and Hofstede 2005). They are, because they are instilled into a society's members from birth. As a baby and as a toddler, a child is primed as a social being. Once a child sets foot into the wider society as a teenager, its basic cultural orientation is firmly in place.

This research stream has led to dimension models of culture. The most widely used of these is the five-dimension model by Hofstede. The five dimensions are about five issues that relate to our basic drives. They will be introduced briefly in order to use them further on in the text. Note that these are not personality traits, but societal patterns! Also note that the picture drawn here is necessarily simplified. It presents the two caricatured extremes of each dimension. In reality, almost all cultures have intermediate positions on almost all dimensions. The dimensions are introduced in the following subsections.

\subsection{Collectivism Versus Individualism}

This dimension is about affiliation. To a collectivist (e.g., East Asian, most non-Western countries) mindset, fixed membership of a single group in which all members are interdependent is the natural state of being human. No member of the natural group can be cast aside. This means that maintaining harmony is crucial.

To an individualist (e.g., North-American, North-west European) mindset, selfsufficiency is the natural state of being. Everybody should be judged in the same way, whether or not the person is a group member. Honest people speak their minds, even if that means open disagreement.

\subsection{Hierarchy: Large Versus Small Power Distance}

This dimension is about dominance as an ascribed quality. It has to do with authority as seen from below. Are parents, teachers, priests and bosses held in awe, and is autocratic leadership expected? Then we have a society of large power distance (e.g., China, India, Russia.).

Or is leadership a role that could change from one person to another with ease, and are all people born equal? In that case, the society is one of small power distance (e.g., Anglo and Germanic countries). 


\subsection{Aggression and Gender: Masculinity Versus Femininity}

This dimension is about assertive dominance, about muscle power, and about the emotional roles of the two sexes. In what is called a masculine society (e.g., Japan, Anglo countries), men in particular are supposed to be fighters. Women are supposed to be cheerleaders to the men's fight — but they have to be tough too. Men try to look and act like real men and women try to look and act like real women. These are tough societies, with strong-handed police and military and with heavy punishment for offenders.

In what is called feminine societies (e.g., Scandinavian countries), both men and women are supposed to be peace-loving and consensus seeking and their social behaviors are not strongly different. Criminals should be helped, not punished.

\subsection{Otherness and Truth: Uncertainty Avoidance}

This dimension is about how to cope with the unknowable. Some societies are termed uncertainty avoiding (e.g., Arab, Latin and Slavic countries). They tend to have strict rules and rituals about things that are strange or different, such as religious rules and food taboos, or strange sexual practices. In these societies, the distinction between clean and dirty is important. In fact they feel that any distinction should be a sharp one. They are concerned about right and wrong, about theory, about arguing for its own sake. They like to show their emotions, particularly anxiety, verbally and non-verbally.

Other societies are termed uncertainty tolerant (e.g., Anglo countries, China, Scandinavia, Vietnam). They are relaxed and curious about strange things and people, and not worried about establishing strict classification schemes for everything. They value exploratory behaviors and novel experiences, and a relaxed communication style.

\subsection{Short Versus Long-Term Gratification of Needs}

This dimension is about all the basic human drives. Which drive should get precedence, one that presses now or one that might become pressing in ten years? Some societies live for today, and these are termed short-term oriented. Behaving in an appropriate manner and respecting conventions is important in these societies, as well as 'keeping up with the Joneses' as the Americans have it. There are strong opinions about good and bad, and these are believed to be immutable.

Other societies live for the future; these are termed long-term oriented (e.g. China, Japan). Reasoning is pragmatic, and principles are adapted to context. Good and bad are seen as complementary and changeable. Planning, foresight and perseverance are valued. On the downside, this could lead to stinginess and calculation.

\subsection{Five Dimensions, One World}

So far in this text, the dimensions of culture have been isolated from one another in an artificial way. In reality, cultures have a recognizable feel to them, a Gestalt that can be described, albeit only roughly, by its combination of dimension scores. The five 
dimensions are no more than abstractions that capture main behavioral trends. Cultures have 'Gestalts' of behavior. Experienced negotiators know the range of behaviors that they can expect from negotiators from other parts of the world. They also know how gender, age, status and personality can affect the negotiation style of people from these parts of the world.

In Hofstede et al. (2006, 2008a,b,c, 2009) the influence of each of the dimensions on trade processes was modeled separately; a slightly artificial, but also necessary intermediate step to model agents differentiated along the Hofstede dimensions. Reconciling these dimensional models into one believable model that shows the "whole negotiator', although still abstracting from personality, is the aim of this article.

\section{Negotiation}

In bilateral negotiation, two parties aim at reaching a joint agreement. They do so by exchanging various offers or bids using e.g. an alternating offers protocol (Osborne and Rubinstein 1994) called the "negotiation dance" in Raiffa et al. (2002). Negotiation is a complex emotional decision-making process aiming to reach an agreement to exchange goods or services (Thompson 2005).

\subsection{Agent Models for Negotiation}

The literature on automated negotiation contains a number of agent models for negotiation. The focus of that literature is on reaching deals that are Pareto-efficient (i.e., neither can improve without making the situation worse for the other). Furthermore, some aim at reaching fair outcomes, i.e., in which the deal is equally good for both parties. The strategies differ in whether or not they take knowledge about the domain, and/or opponent into account. Examples of strategies that do not use any domain or opponent knowledge can be found in Faratin et al. (1998) and Jonker and Treur (2001). Other strategies try to learn the opponent's preferences, see e.g., (Coehoorn and Jennings 2004) and (Hindriks and Tykhonov 2008). The work presented in this paper aims to develop models of actual human behavior. It does not aim to develop an optimal bargaining strategy that can outperform human negotiators or other agents.

\subsection{Focus on Interpersonal Bargaining}

This work focuses on a specific type of negotiations: two persons bargaining about business transactions. Gaming simulations form the context of the bargaining sessions. The gaming simulations are designed as tools in supply chains and networks research (Meijer et al. 2006). In this setting participants negotiate a transaction of a commodity with either base quality or a superior quality. The real quality is known to the supplier and invisible to the customer. The customer can either trust the supplier's quality statement, or request third-party testing at the cost of a fee. A customer may negotiate that the supplier provide certified quality by third-party testing and have the commodity delivered with the test report as a certificate. So, the relevant attributes for comparing bids are price, quality, and certification. 
If the quality is above base level and the transaction is not certified, the customer is exposed to the risk of supplier's opportunism. The valuations of quality and risk have a rational component that can be calculated from market value and probability of deceit. Furthermore, they have a subjective component that is influenced by a trader's personality and culture. The rational component of the valuation of quality is the difference in market price with the price of base quality. The rational component of the valuation of risk is the product of probability of deceit and value of the quality attribute. The subjective valuation comes in addition to the rational value. For quality, it is the trader's quality preference, for instance because of the societal status that results from trading high quality products. For risk, it is an agent's risk aversion. To a risk-averse agent, the absence of risk has a value by itself.

In a culturally homogeneous society, not all agents have equal quality preference and risk aversion. However, significant differences between cultures exist in the average values of these parameters.

\subsection{Agent-Based Market Place (ABMP) and its Application in the Agents}

For the agents' negotiation strategy we chose ABMP (Jonker and Treur 2001), because its similarity to human negotiations has been validated (Bosse et al. 2004). The ABMP process is an exchange of bids, starting with a bid by one of the partners. The other partner evaluates the bid using a utility function that maps a weighted linear combination of bid attributes to the interval $[0,1]$. The weight factors in the utility function represent an agent's preferences. The utility function used in this research is elaborated in a following subsection.

ABMP is a concession strategy. An agent prepares a bid that is a concession to its previous bid. Concession factor $\gamma$ and negotiation speed $\beta$ are the parameters that govern the concession making.

Concession factor $\gamma$ is the fraction of the opening bid's utility that the agent is willing to give in during the negotiation. It determines the minimum utility that is acceptable to an agent, also called the reservation value.

Negotiation speed $\beta$ is the fraction of difference between the agent's previous bid and the minimum utility that an agent uses to determine the target utility of its next bid.

After calculation of the utility of a partner's bid and the target utility of its own next bid, the agent decides whether to accept partners bid or not, governed by the utility gap parameter $\omega$.

Acceptable utility gap $\omega$ is the maximal difference between own target utility and last partner's bid's utility for which an agent will accept partner's bid.

If the target utility minus the partner's last bid's utility is greater than the acceptable utility gap, the agent does not accept and has to decide about its next action. It can terminate the negotiation for several reasons. First, partner's bid may be interpreted as unrealistic if its utility is too far below the minimum utility. Second, an agent may be unsatisfied by the progress in partner's bids. Third, there may be no more room for 
a substantial change of attributes to make a bid with the target utility. In the latter case the agent terminates the negotiation. In the first two cases the probability that an agent terminates the negotiation depends on the impatience parameter $\iota$.

Impatience $\iota$ is the probability that an agent will terminate the negotiation if (a) the utility of partner's bid is less than the cut-off value or (b) progress in the last three rounds is less than the minimal progress required. In the present model the cut-off value $\phi$ is computed from minimum utility $\mu$ :

$$
\phi=(1-\iota) \mu .
$$

Minimal progress $\varphi$ over three rounds of negotiation is computed as

$$
\varphi=(1-\mu) \iota
$$

So, the decisions whether to accept a bid or not and whether to continue or not depend on partner's bid, own last bid, partner's progress, and the values of parameters $\gamma, \beta, \omega$, and $\iota$. Evaluation of bids involves the utility function discussed in the next subsection. This utility function is also used in planning a new bid that has the target utility, taking the agent's quality preference and risk aversion into account.

\subsection{The utility function}

The agent model applies a utility function as proposed by Tykhonov et al. (2008):

$$
U(b)=w_{v} V(b)+w_{q} Q(b)+w_{r} R(b),
$$

with $0 \leq w_{i} \leq 1, i=v, q, r$, and $\sum w_{i}=1$.

$V(b)$ represents the business value of a bid. A customer agent calculates it as

$$
V_{c}=\frac{1-v+q-r_{c}}{2},
$$

with $v$ representing the price of the bid, mapped to the interval $[0,1](0$ represents minimal market price for base quality of the commodity; 1 represents maximal market price for top quality); $q$ in $[0,1]$ (0 represents base quality; 1 top quality); customers cost of risk is calculated as

$$
r_{c}=(1-c)(1-t) q,
$$

with $c=1$ representing presence and $c=0$ absence of a quality certificate; $t$ represents the customers trust in the supplier, defined as the customer's estimate of the probability that the supplier will cooperate and deliver according to contract, even if the supplier has the motive and the opportunity to defect. 
For a supplier the business value of a bid is calculated as

$$
V_{s}=\frac{1+v-q-r_{s}}{2}
$$

with suppliers cost of risk

$$
r_{s}=c f,
$$

where $f$ stands for the certification fee scaled to the same ratio as $v$.

Both customers and suppliers may have a preference in excess of the market value for dealing top quality rather than base quality products. A trader's preference for dealing top quality, even if profits from base quality trade are superior, is represented by $w_{q}$; in the present model $Q(b)$ is computed as:

$$
Q=q-0.5
$$

Some traders may be risk-averse, in which case $w_{r}$ is positive. In the present simulation suppliers are informed about the actual quality level, so

$$
R_{s}=0
$$

For risk-avoiding customers the absence of risk may have a value in itself, which is represented as follows in the present model:

$$
R_{c}=0.5-r_{c}
$$

\section{Culture and Bargaining}

Hofstede et al. (2006, 2008a,b,c, 2009) modeled the influence of culture on trade processes for each of the five dimensions separately. From these papers, the narrative descriptions of the influences of the dimensions on trade negotiations-i.e. the bargaining about transactions_-are cited below.

\subsection{Power Distance (Hofstede et al. 2009)}

Traders from egalitarian cultures may have different ways to negotiate, but they will always negotiate. Traders from large power distance cultures on the other hand are not used to negotiate seriously. The powerful dictate the conditions. The less powerful have to accept. In feminine or collectivist cultures the powerful may exercise restraint, or the lower ranked may successfully plead for compassion, but this is not a joint decision making process like a negotiation is. The higher ranked partner decides. When people from hierarchical cultures are forced to negotiate, because they are in a position of equal status or trade with foreigners, the negotiations often end in a game of power.

The higher ranked in hierarchical societies prefer top quality commodities to stress their position. They accept risk, because they do not expect the lower ranked to deceive 
them. The lower ranked on the other hand, avoid risk and protect themselves by settling for base quality commodities.

A trader from a culture with large power distance expects a lower ranked business partner to accept his conditions rapidly. If the lower ranked partner has the same cultural background, there is no problem and the rights of the higher ranked will be recognized and respected: the lower ranked will be modest and give in easily. However, a trader from an egalitarian culture will not give in to the pressure if his status is lower, but will either react furiously (e.g., break off negotiations) or simply ignore the pressure (make a counterproposal), in which case the opponent will be furious.

If a trader from a culture with large power distance negotiates with a foreigner and assumes the foreigner to have a higher status, he may give in more easily than the foreigner expected. In that case the foreigner may be happy, but his opponent will not have his fair share. If both are from hierarchical cultures but do not perceive one another's hierarchical position they may make misattributions resulting in one of them being dominated or stopping the negotiations.

\subsection{Uncertainty Avoidance (Hofstede et al. 2008b)}

Uncertainty avoiding traders have an emotional style of negotiation, making sure that the opponents understand their feelings. They will not adapt their behavior to their opponent's. They are quality-minded and avoid risk in business transactions, especially when dealing with strangers. For uncertainty avoiding traders, time is money. They want to go directly to their target, and are impatient. After a few unsuccessful iterations, the uncertainty avoiding trader will break off the negotiation.

Uncertainty tolerant traders on the other hand have a relaxed style of negotiation. They try to adapt their behavior to their counterparts, although they are not prepared to come to an agreement at all cost. They do not show their emotions and may be disconcerted if their opponents do. They are careful not to be more yielding than their counterparts are, not especially modest, and are ready to break off negotiations in case of insufficient progress.

\subsection{Individualism and Collectivism (Hofstede et al. 2008a)}

For a collectivistic trader negotiation has to be preceded by the formation of a relationship. If that goes wrong there will be no negotiation. During the negotiation, collectivist traders discriminate between in-group and out-group partners. They feel obliged to be more conceding to an in-group partner, are more hesitant to break off negotiations with in-group partners, and will try to maintain harmony as long as the opponent follows the in-group rules. Breaking the rules asks for a reaction. The style of that reaction may be furious, or they might never explicitly say anything, but just avoid the other from now on. The reply to a proposal from an in-group partner will be modest, but there is no need to be modest to an out-group partner. If an out-group partner replies with no or small concession, negotiation is likely to be broken off, where an in-group partner or an acquainted relation would get a second chance. 
Responsibility for in-group welfare and compliance with in-group rules always play a prominent role in a collectivistic culture. A collectivist will accept benefits for his in-group rather than his personal advantage as a convincing argument.

Individualists have one thing in mind during negotiations: their own personal interest. Depending on their personality and incentives, this might be the material advantage of the deal in question, or the development of new long-term trusting relations with perspectives of future deals, or just the pleasant conversation during the negotiations, or the satisfaction of winning the game, but one thing stands for sure: individualists pursue private interests. So individualist traders are not very modest in their negotiations, nor will they give in for the purpose of maintaining harmony. If they are not aware of the cultural differences when trading with collectivists, they may be upset by the lack of explicit communication, or they may upset their opponents by being too explicit, or by talking business before the relationship has been established and acknowledged. They are not particularly patient or impatient negotiators, but behave patiently as long as it serves their interest.

\subsection{Masculinity and Femininity (Hofstede et al. 2006)}

The dimension of masculinity versus femininity can be interpreted as a preference for performance versus cooperation. A performance oriented trader (masculine culture) is interested in fast trades, with as many top quality goods as possible in one trade. This trader is rather impatient, and if bids are too far off from his profile, he will walk away quickly. The performance oriented sticks to the contract of the deal, deceive the trade partner to the limits of the contract without any compunction, and expects the partner to do so too. Each subsequent negotiation will be dealt with without taking past trustworthiness into account. Each new contract will be set up from scratch. The trader learns from mistakes to make sure that the contract will not lead to new and uncomfortable surprises on his side.

A cooperation oriented trader (feminine culture) is interested in the relationship with the trade partner; building trust is important. The amount of goods or quality level is not of the most interest, because the relationship built during negotiation might pay off in future negotiations. Given the interest in the relationship with the trade partner, a first negotiation with a trade partner will take time that is willingly spent by the trader. During such negotiations, the trader appreciates a negotiation process in which both partners show a willingness to accommodate the other over time. Past negotiations do play an important role in subsequent negotiations. The trader is perfectly willing to see the current negotiation as a kind of continuation of the previous one. If the trade is about the same kind of commodity, the trader will start the negotiation from the deal of the last one. If the other accepts, then the deal can be made in one round and in seconds, whereas the first deal might have taken a lot of rounds and lots of time.

\subsection{Long- Versus Short-Term Orientation (Hofstede et al. 2008c)}

Long term oriented negotiators are pragmatic and take the bigger picture. They tend to see one bargaining instance as a small step in a long process, and their decisions 
will be led by their estimation of the profitability or other success chances of that longer process. Long-term oriented traders show patience. They do not rapidly break off negotiations. They do not overcharge, but they do not rapidly give in.

Short term oriented negotiators, on the other hand, think in terms of moral principles and apply them to the situation that is before them here and now. They are very reliable when it comes to following standards of appropriateness of behavior, but this can make them disregard the ulterior consequences of their actions. They are conceding and patient with high-status partners and do not show them distrust. Otherwise they follow an opportunistic quality strategy.

\section{Modeling Culture in ABMP}

The model of the effects of culture on ABMP parameters and utility weight factors is based on the narrative descriptions in the preceding section. The descriptions indicate if a parameter is to be increased or decreased along each of Hofstede's dimensions. Table 1 summarizes the direction of the effects (increasing versus decreasing).

Some cultural dimensions have a direct effect on the parameter values, but in other cases the influence depends on the relationship with the partner:

- The societal status of an agent and that of its partner affect behavior in societies where power distance matters.

- Also in short-term oriented societies, partner's status is relevant.

Table 1 Influence of culture on the utility weight factors and ABMP parameters

\begin{tabular}{|c|c|c|c|c|c|c|c|}
\hline Culture type & Conditions & $w_{q}$ & $w_{r}$ & $\gamma$ & $\beta$ & $\omega$ & $\iota$ \\
\hline \multirow[t]{4}{*}{ Large power d. } & Self status high & + & & & & & \\
\hline & Self status low & - & & & & & \\
\hline & Higher partner & & + & + & & $+!$ & - \\
\hline & Lower partner & & - & & & & \\
\hline \multicolumn{8}{|l|}{ Small power d. } \\
\hline \multirow[t]{2}{*}{ Uncertainty av. } & Similar partner & + & + & & + & & + \\
\hline & Different p. & + & ++ & & + & & + \\
\hline \multicolumn{8}{|l|}{ Uncer. tolerant } \\
\hline \multicolumn{8}{|l|}{ Individualistic } \\
\hline \multirow[t]{2}{*}{ Collectivistic } & Ingroup partner & & & + & & & - \\
\hline & Outgroup p. & & + & & - & & \\
\hline Masculine & & + & + & & + & & + \\
\hline Feminine & & - & & & - & & - \\
\hline Long-t. oriented & & - & & & & & - \\
\hline \multirow[t]{2}{*}{ Short-t. oriented } & General & + & & & & & \\
\hline & High partners & + & - & + & & & - \\
\hline
\end{tabular}

$w_{q}$ Quality preference; $w_{r}$ Risk aversion; $\gamma$ Concession factor; $\beta$ Negotiation speed; $\omega$ Acceptable utility gap; ı Impatience; + Increased parameter value; - Decreased; + ! Increased every negotiation round 
- Members of uncertainty avoiding societies distrust strangers more than people they are familiar with.

- Common group membership and group distance are important in collectivistic societies.

In the model the agents are labeled with tags that indicate status and group membership. The tags are visible to other agents so that they can estimate status difference and group distance. The model combines effects of culture with effects of status and group membership.

The effects on negotiation parameters and weight factors are modeled as follows.

(1) The Hofstede indices PDI, UAI, IDV, MAS, and LTO position national cultures on the five dimensions. They are known for many countries (see, e.g., Hofstede 2001). Let $H, A, I, M$, and $L$, respectively, represent the indices as real values scaled to $[0,1]$, so that $H=1$ represent maximal power distance, $(1-H)=1$ represent maximal egalitarianism, etc. Thus, there are 10 cultural stereotypes.

(2) Status and group distance are represented as real values in [0,1]. Where status, status difference and group distance are relevant, the effect is conditional upon the value of a cultural index. For instance, the product $(1-I) g$ represent the effect of group distance $g$ in conjunction with collectivism $(1-I)$; in a maximally individualistic society, $1-I=0$, so group distance $g$ has no effect.

(3) As indicated in Table 1, some of the cultural stereotypes may have a positive, monotonously increasing, effect on a particular parameter value; other stereotypes may have a negative, monotonously decreasing, effect.

(4) For each parameter there may be a set of positive effects and a set of negative effects. The joint effect of a set of effects working with equal sign is weakly disjunctive, i.e. the joint effect equals the maximum of the effects of the individual dimensions ${ }^{1}$ (e.g., if we model statement "people from uncertainty avoiding or masculine societies prefer rapid negotiations", then the joint effect is the maximum of the effects of uncertainty avoiding and masculinity).

(5) The resulting joint negative effects are assumed to compensate for joint positive effects, vice versa: the effect on parameter $x$ is the difference of the joint positive and joint negative effects.

$$
e_{x}=e_{x+}-e_{x-}
$$

One can, for instance, represent the effect "in hierarchical societies parameter $x$ is increased in case of status difference, unless the society is collectivistic or feminine" as follows:

$$
e_{x}=e_{x, H\left(s_{i}-s_{j}\right)}\left[H\left(s_{i}-s_{j}\right)\right]-\max \left\{e_{x,(1-I) g}[(1-I) g], e_{x, 1-M}(1-M)\right\},
$$

\footnotetext{
1 Weak disjunction is taken as the formalism to combine effects of cultural dimensions working in the same direction, because it takes only the stronger of the dimensions into account. This is to be preferred to, for instance, linear combinations, or (weighted) geometrical averaging, because in those cases a strong effect of a high value of one dimension would be conditional upon high values of the other dimensions. Weak disjunction is also preferred to stronger forms of disjunction, because combination of moderate values of several dimensions must not have a strong joint effect.
} 
Where $e_{x, D}$ represent a function that computes the effect of $D$ on $x$. No actual evidence for the form or the range of the functions is available. In the current model we assume linear relations with range $[0,1]$ for $e_{x, D}$, so the above example would reduce to

$$
e_{x}=H\left(s_{i}-s_{j}\right)-\max [(1-I) g, 1-M]
$$

(6) Joint positive and joint negative effects deduced from Table 1 are presented in Table 2.

(7) The actual value of $x$ is assumed to be a function that maps $x_{T}$ (the typical value of $x$ ) and the effect $e_{x}$ to a range $\left[x_{L}, x_{H}\right], x_{L} \leq x_{T} \leq x_{H}$. In the current model we take a simple approach and use linear interpolation:

$$
x=x_{T}+\frac{e_{x}+\left|e_{x}\right|}{2}\left(x_{H}-x_{T}\right)+\frac{e_{x}-\left|e_{x}\right|}{2}\left(x_{T}-x_{L}\right)
$$

(8) The utility weights $w_{i}, i=v, q, r$, are to be normalized for proper functioning of ABMP. Culturally adjusted values of $w_{q}^{\prime}$, and $w_{r}^{\prime}$ (see Table 2) are relative to $w_{v}^{\prime}=1$, so:

$$
w_{i}=\frac{w_{i}^{\prime}}{1+w_{q}^{\prime}+w_{r}^{\prime}}
$$

(9) The culturally adjusted parameter values and weight factors resulting from rules (1)-(8) are used in the ABMP evaluation of bids, in the decisions (to accept or not; to continue or not; see Hofstede et al. 2006), and in the planning of a new bid. In each round of the negotiation, the parameters are recomputed.

The next section presents results obtained from this model.

\section{Test Runs}

The models discussed in the previous sections, including the ABMP architecture, are implemented in a multi-agent simulation, where agents can select trade partners, negotiate business transactions with price, quality, and certification as attributes, deliver truthfully or opportunistically, have deliveries tested for quality, and update beliefs about partners according to experiences in negotiations and testing. The simulation environment is implemented in Cormas. ${ }^{2}$

The model was tested for correct implementation. The observed variables were:

- The number of successful negotiations (i.e. terminated with a contract) in runs of 200 time steps with a population of 8 supplier agents and 8 customers;

- The percentage of negotiations that failed, i.e. that were terminated by one of the agents before agreement was reached;

\footnotetext{
2 http://cormas.cirad.fr/indexeng.htm
} 
Table 2 Formulas for the effects of culture on negotiation parameters; $H, A, I, M$, and $L$ represent the scaled Hofstede indices; $s_{i}$ represent the agent's societal status in $[0,1] ; s_{j}$ partner's status; group distance $g$ between the agent and partner is computed from agent labels, with 0 representing minimal distance, 1 maximal distance; $\rho$ represent the round number in the current negotiation

\begin{tabular}{lll}
\hline$x$ & Increasing effect $e_{x}+$ of culture on $x$ & Decreasing effect $e_{x}$ of culture \\
\hline$w_{q}^{\prime}$ & $\max \left(H s_{i}, A, M, 1-L\right)$ & $\max \left[H\left(1-s_{i}\right), 1-M, L\right]$ \\
$w_{r}^{\prime}$ & $\max \left[\begin{array}{l}\left.H\left(s_{j}-s_{i}\right), A, \sqrt{A g},\right] \\
(1-I) g, M\end{array}\right]$ & $\max \left[H\left(s_{i}-s_{j}\right),(1-L) s_{j}\right]$ \\
$\gamma$ & $\max \left[\begin{array}{l}H\left(s_{j}-s_{i}\right),(1-I)(1-g), \\
(1-L) s_{j}\end{array}\right]$ & \\
$\gamma^{\prime}$ & $\max [A, M]$ & $\max [(1-I) g, 1-M]$ \\
& $H\left(s_{j}-s_{i}\right) \rho$ & $\max \left[\begin{array}{l}H\left(s_{j}-s_{i}\right),(1-I)(1-g), \\
(1-M), L,(1-L) s_{j}\end{array}\right.$ \\
\hline
\end{tabular}

- The percentage of successful negotiations leading to top quality transactions, as a measure of willingness to accept risk.

In all test runs, the agents were set to be neutral with respect to trust, i.e. they had no information whether their partners were trustworthy or not $(t=0.5)$. The option of certification was switched of, so that agents were forced to accept risk if they bought top quality products.

The following hypotheses about agents behavior in this environment are formulated on the basis of the narrative descriptions in this article's section on culture and bargaining.

H1 In hierarchical societies (large power distance), high-ranked agents buy top quality products; low-raked agents buy basic quality products to protect themselves from risk.

H2 In hierarchical societies, high-ranked agents are more successful trading with low-ranked than with equal-status partners, because lower-ranked yield.

H3 In uncertainty avoiding societies, high quality products are preferred, but agents are risk-avoiding and impatient. Therefore, trade proceeds less smooth in uncertainty avoiding than in uncertainty tolerant societies.

H4 In uncertainty avoiding societies, inter-group trade fails more often than in-group trade.

H5 In collectivistic societies, in-group trade runs smoother than inter-group trade.

H6 In masculine societies, agents deal rapidly but many negotiations fail, due to the combination of impatience and high quality ambitions.

H7 In feminine societies, negotiations proceed slowly, but with a low failure rate.

H8 In short-term oriented societies, agents prefer top quality. 
Table 3 Average results of simulated negotiations for cultural stereotypes, with the value for the particular dimension set to either 0.1 or 0.9 and the values for the other dimensions set to 0.5 ( 8 suppliers; 8 customers; 10 runs of 200 time steps for each configuration; parameter values as in Table 4)

\begin{tabular}{llclc}
\hline Culture type & Conditions & Number of transactions & \% Failed negotiations & $\%$ Top quality \\
\hline Large power d. & Self status high & 44 & 57 & 97 \\
& Self status low & 50 & 60 & 0 \\
& Customer higher & 77 & 45 & 98 \\
& Supplier higher & 4 & 92 & 0 \\
Small power d. & & 72 & 49 & 2 \\
Uncertainty av. & Similar partner & 29 & 71 & 76 \\
& Different p. & 27 & 73 & 87 \\
Uncer. tolerant & & 49 & 58 & 1 \\
Individualistic & & 66 & 50 & 1 \\
Collectivistic & Ingroup partner & 117 & 13 & 61 \\
& Outgroup p. & 39 & 65 & 0 \\
Masculine & & 36 & 71 & 80 \\
Feminine & & 61 & 45 & 0 \\
Long-term or. & & 55 & 52 & 0 \\
Short-term or. & General & 24 & 72 & 95 \\
& High customers & 57 & 47 & 91 \\
\hline
\end{tabular}

H9 In short-term oriented societies, agents are more conceding toward high-status partners. This leads to rapid transactions and low failure rate if partner's status is high.

To test the hypotheses, the model was run for each of the configurations of culture, status and group membership represented in Table 1. To simulate a cultural stereotype, the value of one normalized index $(H, A, I, M$, or $L)$ was set to 0.1 or 0.9 , while the values of the other normalized indices were set to 0.5 . In all runs, group distance between suppliers and customers was set to 1 , except in the runs simulating uncertainty avoiding and collectivistic societies with in-group partners, where group distance was set to 0 . Status was set to 0.5 for all agents, except in the runs where status difference mattered. In the latter case the status of either suppliers or customers was set to 0.1 and that of their counterparts to 0.9 .

For each configuration, 10 runs (with different random generator seed) were made. Each run lasted 200 time steps with a population of 8 supplier agents and 8 customers. In 200 time steps 8 pairs can complete approximately 100 negotiations together, so for each configuration a total of approximately 1,000 negotiations were completed (successfully or unsuccessfully).

Table 3 presents average results per run of simulated negotiations, using the parameter settings displayed in Table 4 . In the following paragraphs the results are compared with the hypotheses. 
Table 4 Parameter values used in the simulation runs

\begin{tabular}{lllllll}
\hline Type of value & $w_{q}^{\prime}$ & $w_{r}^{\prime}$ & $\gamma$ & $\beta$ & $\omega$ & $\iota$ \\
\hline Typical value $x_{T}$ & 0.1 & 0.1 & 0.7 & 0.2 & 0.02 & 0.3 \\
Maximal value $x_{H}$ & 0.5 & 0.5 & 1 & 0.5 & 0.1 & 0.7 \\
Minimal value $x_{L}$ & 0 & 0 & 0 & 0 & 0 & 0.1 \\
\hline
\end{tabular}

$w_{q}^{\prime}$ Quality preference; $w_{r}^{\prime}$ Risk aversion; $\gamma$ Concession factor; $\beta$ Negotiation speed; $\omega$ Acceptable utility gap; ८ Impatience

H1 is confirmed. In hierarchical societies, the higher-status agents buy top quality products and accept the associated risk. The lower-status agents buy basic quality products.

H2 is partly confirmed. In this simulation the higher-ranked agents succeed in enforcing transactions only in the consumer role. In the supplier role the higher-ranked supplier agents insist on selling top quality to lower-ranked agents and the lowerranked keep asking for basic quality until the suppliers break-off.

H3 is confirmed. In uncertainty avoiding societies, top quality is dominantly traded and transaction success is lower than in uncertainty tolerant societies.

H4 is confirmed. In uncertainty avoiding agent societies, transactions with strangers mostly fail.

H5 is confirmed. In collectivistic societies, in-group trade runs smoothly and agents show trust in each other, trading top quality products. Collectivist inter-group trade is less efficient than in-group trade and also less efficient than trade in individualistic societies.

H6 is confirmed. Failure rate is high in the masculine society.

H7 is confirmed. Failure rate is low in the feminine society and negotiations proceed relatively slow.

H8 is confirmed. The agents in the short-term oriented societies dominantly trade top quality products.

H9 is confirmed. When trading with high-ranked customers, transaction rate is high and failure is low in short-term oriented societies.

These results comply with the expected behavior of the agents and verify the implementation. However, they do not validate that the implemented model generates believable culturally differentiated agent behavior.

For that purpose results produced by this model can be compared with results known from intercultural negotiation literature. For instance, Brett and Okumura (1998) report that joint gains in intercultural negotiations between Japanese and USA negotiators were lower than in either Japanese-Japanese or USA-USA negotiations. These situations are tested with the present model. All agents are assumed to have equal status. Japanese culture is more uncertainty avoiding and collectivistic than USA culture. Group distance experienced by the negotiators is expected to be very relevant in Japan. To verify this effect, tests are run with maximal group distance $g=1$ and reduced group distance $g=0.5$ for the intra-cultural negotiations. In human negotiations, the effect of group distance can be reduced by getting acquainted, but we assume that Japanese agents will still experience USA agents more as strangers than out-group 
Table 5 Average results of simulated negotiations between agents configured with cultural dimensions similar to Japan $(H=0.5, A=0.9, I=0.4, M=0.9, L=0.8)$ and USA $(H=0.4, A=0.5, I=$ $0.9, M=0.6, L=0.3$ ) (8 suppliers; 8 customers; 10 runs of 200 time steps; parameter values as in Table 4; status $=0.5$ for all agents)

\begin{tabular}{llccc}
\hline Supplier/customer & Group distance & Number of transactions & \% Failed negotiations & \% Top quality \\
\hline USA/USA & $g=1$ & 31 & 70 & 70 \\
Japan/Japan & $g=1$ & 9 & 90 & 0 \\
USA/USA & $g=0.5$ & 32 & 70 & 69 \\
Japan/Japan & $g=0.5$ & 43 & 60 & 23 \\
USA/Japan & $g=1$ & 0 & 100 & 37 \\
Japan/USA & $g=1$ & 19 & 81 & 0 \\
USA/Japan & $g=0.7$ & 7 & 93 & 38 \\
Japan/USA & $g=0.7$ & 22 & 79 &
\end{tabular}

Japanese agents. Therefore, intercultural tests are run with $g=1$ and $g=0.7$. For The hypotheses to be tested in this situation are:

H10 Japanese agent's negotiation results strongly depend on group distance.

H11 Intercultural negotiations between simulated USA and Japanese agents are less efficient than intra-cultural negotiations in those countries.

H12 Even if group distance is reduced, better results are obtained in a culturally homogeneous than in an intercultural setting.

The results presented in Table 5 confirm the hypotheses. USA agents are not very sensitive to group distance, but Japanese are. Under the assumption that Japanese agents experience larger group distance with USA than with other Japanese, H11 and $\mathrm{H} 12$ are confirmed. The difference in results with USA and Japan in customer versus supplier role is caused by differences in risk attitude.

The second example of results obtained with realistic cultural indices is based on results of human gaming simulations by Meijer et al. (2006). One of their findings is that Dutch buyers prefer to trust their suppliers with respect to agreements to deliver top quality products, while buyers from the USA prefer certification and third party testing. Simulations were run to test if the model could simulate this effect. For this test the following parameter settings were modified:

- quality preference $w_{Q}^{\prime}$ was raised to 0.2 (to stimulate to top quality trade);

- trust in each other agent was set to $t=0.8$ (to enable trusting behavior);

- the certification option was switched on, i.e. buyers had the opportunity to demand a certificate, which incurs extra cost on the suppliers (10\% of the maximum price of top quality products) and thereby raises price.

All agents are equally configured, except for culture. The hypothesis is:

H13 Agents configured as Dutch buyers are more inclined to trust than USA agents; customer agents configured with USA culture are more inclined to pay for certified quality than Dutch agents.

The results presented in Table 6 confirm this hypothesis. 
Table 6 Average results of simulated negotiations between agents configured with cultural dimensions similar to Dutch $(H=0.4, A=0.5, I=0.8, M=0.1, L=0.4)$ and USA $(H=0.4, A=0.5, I=$ $0.9, M=0.6, L=0.3$ ) (8 suppliers; 8 customers; 5 runs of 200 time steps; parameter values as in Table 4, except typical value of $w_{Q}^{\prime}=0.2$ )

\begin{tabular}{llllc}
\hline Supplier/Customer & $\begin{array}{l}\text { Number of } \\
\text { transactions }\end{array}$ & $\begin{array}{l}\text { \% Failed } \\
\text { negotiations }\end{array}$ & \% Top quality & $\begin{array}{l}\text { \% Certified } \\
\text { transactions }\end{array}$ \\
\hline USA/USA & 48 & 54 & 89 & 15 \\
Dutch/Dutch & 50 & 48 & 94 & 7 \\
Dutch/USA & 54 & 49 & 91 & 13 \\
USA/Dutch & 45 & 57 & 93 & 4 \\
\hline
\end{tabular}

\section{Conclusion}

Negotiation can be approached as a rational process of collaborative decision making, as advocated by Raiffa et al. (2002). However, it is observed that negotiation outcomes differ across the world and that people from different countries differ with respect to the way they negotiate and the results they obtain (Gelfand and Brett 2004). As to all forms of negotiations, this applies to business negotiations and the bargaining about commercial transactions. There is abundant evidence that the result of decision making in business is influenced by the cultural background of the decision makers (e.g., Graham et al. 1994; Adair et al. 2004; Metcalf et al. 2006) or institutional differences across countries (e.g., Kumar and Worm 2004), the development of which is also influenced by culture (Hofstede 2001). Therefore, agent-based simulations of international supply chains and networks should account for cultural differences.

De Rosis et al. (2004) suggested to explore the feasibility of Geert Hofstede's fivedimensional model (Hofstede 2001) to differentiate agents' behavior across cultures. The present paper shows how Hofstede's theory can be used for this purpose, in a multi-agent simulation of international trade.

In contrast with models that aim to optimize rational decision making, the model should in this case realistically simulate human negotiation behavior. The ABMP negotiation architecture (Jonker and Treur 2001) was validated to satisfy this requirement by Bosse et al. (2004) . Therefore, the ABMP architecture is chosen as the basis for modeling cultural differences. A model has been developed for the joint effect of the dimensions of culture on ABMP parameters, based on earlier work that modeled the separate effects of individual dimensions (Hofstede et al. 2006, 2008a,b,c, 2009).

The model proposed in this paper has been tested on imaginary stereotypical cultures that differ on only one of the dimensions. Tendencies in the results along each of the dimensions comply with what is expected on the basis Geert Hofstede's theory. The tests with the stereotypical cultures confirm that the model is sensitive to variations of the cultural indices in the desired direction. Further testing with combinations of dimensions that are drawn from actual cultures should give evidence of the model's validity.

Two examples are given of simulations of results of negotiation research reported in business science literature. The simulations reproduce qualitative aspects of the 
cases reported in that literature, thus confirming that the model can reproduce actual cultural effects. However, this does not provide a full validation of the model. It is a test that confirms the model's sensitivity for relevant parameters. Validation and tuning of parameters require more simulations of actual cases from literature or experiments.

\section{References}

Adair W, Brett J, Lempereur A, Okumura T, Shikhirev P, Tinsley C, Lytle A (2004) Culture and negotiation strategy. Negot J 20:87-111

Bosse T, Jonker CM, Treur J (2004) Experiments in human multi-issue negotiation: analysis and support. In: Proceedings of the third international joint conference on autonomous agents and multi-agent systems, pp 672-679

Brett JM, Okumura T (1998) Inter- and intracultural negotiation: US and Japanese negotiators. Acad Manag J 41:495-510

Coehoorn RM, Jennings NR (2004) Learning an opponent's preferences to make effective multi-issue negotiation trade-offs. In: Proceedings of 6th international conference on e-commerce, pp 59-68

de Rosis F, Pelachaud C, Poggi I (2004) Transcultural believability in embodied agents: a matter of consistent adaptation. In: Payr S, Trappl R (eds) Agent Culture. Lawrence Erlbaum Associates, pp 75-105

Faratin P, Sierra C, Jennings NR (1998) Negotiation decision functions for autonomous agents. Robo Auton Syst 24:159-182

Gelfand MJ, Brett JM (2004) The handbook of negotiation and culture. Stanford University Press, Stanford

Graham JL, Mintu AT, Rodgers W (1994) Exploration of negotiation behaviors in ten foreign countries using a model developed in the United States. Manag Sci 40:72-95

Hindriks K, Tykhonov D (2008) Opponent modeling in automated multi-issue negotiation using Bayesian learning. In: Proceedings of the seventh international conference on autonomous agents and multiagent systems, pp 331-338

Hofstede G (2001) Culture's Consequences. 2. Sage Publications, Thousand Oaks

Hofstede G, Hofstede GJ (2005) Cultures and organizations: software of the mind, third millennium edition. McGraw-Hill, New York

Hofstede GJ, Jonker CM, Meijer S, Verwaart T (2006) Modeling trade and trust across cultures. In: Stølen K, et al (eds) Trust management: 4th international conference, iTrust 2006. Springer-Verlag, pp 120-134

Hofstede GJ, Jonker CM, Verwaart T (2008a) Individualism and collectivism in trade agents. In: Nguyen NT, et al (eds) New frontiers in applied artificial intelligence, IEA/AIE 2008. Springer-Verlag, pp 492-502

Hofstede GJ, Jonker CM, Verwaart T (2008b) Modeling culture in trade: uncertainty avoidance. In: 2008 Agent-directed simulation symposium (ADSS'08), Spring Simulation Multiconference 2008. SCS, pp 143-150

Hofstede GJ, Jonker CM, Verwaart T (2008c) Long-term orientation in trade. In: Schredelseker K, Hauser F (eds) Complexity and artificial markets. Springer, pp 107-118

Hofstede GJ, Jonker CM, Verwaart T (2009) Modeling power distance in trade. In: David N, Sichman JS (eds) Multi-agent-based simulation IX, international workshop, MABS 2008, Revised Selected Papers. Springer, pp 1-16

Jonker CM, Treur J (2001) An agent architecture for multi-attribute negotiation. In: Nebel B (ed) Proceedings of the 17th international joint conference on AI, IJCAI '01, pp 1195-1201

Kumar R, Worm V (2004) Institutional dynamics and the negotiation process: comparing India and China. Int J Confl Manag 15:304-334

Meijer S, Hofstede GJ, Beers G, Omta SWF (2006) Trust and tracing game: learning about transactions and embeddedness in a trade network. Prod Plan Control 17:569-583

Metcalf LE, Bird A, Shankarmahesh M, Aycan Z, Larimo J, Valdelamar DD (2006) Cultural tendencies in negotiation: a comparison of Finland, India, Mexico, Turkey and the United States. J World Bus 41:382-394

Osborne MJ, Rubinstein A (1994) A course in game theory. The MIT Press, Cambridge

Raiffa H, Richardson J, Metcalfe D (2002) Negotiation analysis: the science and art of collaborative decision making. Harvard University Press, Cambridge 
Smith P (2004) Nations, cultures, and individuals: new perspectives and old dilemmas. J Cross-Cult Psychol 35:50-61

Thompson LL (2005) The mind and heart of the negotiator. 3. Pearson Prentice Hall, Upper Saddle River

Tykhonov D, Jonker C, Meijer S, Verwaart T (2008) Agent-based simulation of the trust and tracing game for supply chains and networks. J Artif Soc Soc Simul 11(3):1 http://jasss.soc.surrey.ac.uk/11/3/1. html 